\title{
Response to Inhaled Nitric Oxide Predicts Survival in Patients With Pulmonary Hypertension
}

\author{
RICHARD A. KRASUSKI, MD,${ }^{1}$ GANESH P. DEVENDRA, BA, ${ }^{2}$ STEPHEN A. HART, BS, ${ }^{3}$ ANDREW WANG, MD, ${ }^{4}$ \\ J. KEVIN HARRISON, MD, ${ }^{5}$ AND THOMAS M. BASHORE, MD $^{6}$ \\ Cleveland, Ohio; and Durham, North Carolina
}

\begin{abstract}
Objective: To examine the ability of vasodilator response to predict survival in a diverse cohort of patients with pulmonary hypertension $(\mathrm{PH})$.

Patients \& Methods: A total of 214 consecutive treatment-naive patients referred for invasive PH evaluation were enrolled between November 1998 and December 2008. Vasoreactivity was assessed during inhalation of 40 parts per million nitric oxide (iNO) and vasodilator responders were defined as those participants who achieved a mean pulmonary artery pressure (PAP) of $\leq 40 \mathrm{~mm} \mathrm{Hg}$ and a drop in mean PAP $\geq$ the median for the cohort (13\%). Kaplan-Meier analysis and Cox proportional hazards modeling were used to identify predictors of survival.

Results: There were 51 deaths (25.9\%) over a mean follow-up period of 2.3 years. Kaplan-Meier analysis demonstrated that vasodilator responders had significantly improved survival $(P<.01)$. Vasodilator responders had improved survival regardless of whether or not they had idiopathic or nonidiopathic $\mathrm{PH}$ $(P=.02, P<.01)$ or whether or not they had Dana Point class 1 or non-Dana Point class $1 \mathrm{PH}$ $(P<.01, P=.01)$. In multivariate modeling, advanced age, elevated right atrial pressure, elevated serum creatinine, and worsened functional class significantly predicted shorter survival $(P=.01, P=.01, P=$ $.01, P<.01)$, whereas vasodilator response predicted improved survival $(P=.01)$.

Conclusions: Vasodilator responsiveness to iNO is an important method of risk stratifying PH patients, with results that apply regardless of clinical etiology. (J Cardiac Fail 2011;17:265-271)

Key Words: Vasodilator challenge, pulmonary hypertension, pulmonary arterial hypertension, mortality.
\end{abstract}

Pulmonary hypertension (PH) is a devastating disease characterized by endothelial dysfunction of the small pulmonary arteries. ${ }^{1,2}$ Three general abnormalities of these vessels have been noted: inappropriate smooth muscle

From the ${ }^{1}$ Director of Adult Congenital Heart Disease Service, Division of Cardiovascular Medicine, Cleveland Clinic Foundation, Cleveland, $\mathrm{OH}$; ${ }^{2}$ Cleveland Clinic Lerner College of Medicine of Case Western Reserve University, Cleveland, $\mathrm{OH} ;{ }^{3}$ Cleveland Clinic Lerner College of Medicine of Case Western Reserve University, Cleveland, $\mathrm{OH} ;{ }^{4}$ Division of Cardiology, Department of Medicine, Duke University Medical Center, Durham, NC; ${ }^{5}$ Division of Cardiology, Department of Medicine, DukeUniversity Medical Center, Durham, NC and ${ }^{6}$ Division of Cardiology, Department of Medicine, DukeUniversity Medical Center, Durham, NC.

Manuscript received September 29, 2010; revised manuscript received November 18, 2010; revised manuscript accepted November 22, 2010.

Reprint requests: Richard A. Krasuski, MD, Desk J2-4, Cardiovascular Medicine, Cleveland Clinic Foundation, 9500 Euclid Ave, Cleveland, OH 44195. Tel: (210) 445-7433; Fax: (210) 445-6163. E-mail: krasusr@ccf.org See page 270 for disclosure information.

1071-9164/\$ - see front matter

(C) 2011 Elsevier Inc. All rights reserved.

doi:10.1016/j.cardfail.2010.11.010 proliferation and abnormal remodeling, dysfunctional hemostasis favoring thrombosis, and abnormal regulation of vascular tone. These changes lead to progressive increases in the pulmonary artery (PA) pressure and pulmonary vascular resistance (PVR) and eventually result in right ventricular failure and death. ${ }^{3}$

The natural history of the disease was originally characterized by a National Institutes of Health registry which showed survival rates of $68 \%, 48 \%$, and $34 \%$ at 1,3 , and 5 years, respectively. ${ }^{4}$ Medical therapy for $\mathrm{PH}$ has greatly advanced over the past decade, particularly with the development of prostaglandins, ${ }^{5-7}$ endothelin antagonists, ${ }^{8-13}$ and selective phosphodiesterase inhibitors. ${ }^{14-16}$ Unfortunately, these medications remain costly and are limited by drug-specific toxicities. ${ }^{10,17}$ Guidelines and position papers have established pulmonary vasodilator testing as an appropriate first step in selecting therapy. ${ }^{18,19}$ Rich and colleagues published the seminal study establishing the role for assessing pulmonary vasoreactivity in $1992 .^{20}$ They 
administered calcium channel blockers to 64 patients with idiopathic pulmonary hypertension and found a $26 \%$ response rate according to a definition of $20 \%$ drop in PA pressure and PVR. Responders were then treated indefinitely with high doses of calcium channel blockers. Survival in acute responders was $95 \%$ at 5 years, whereas only $\sim 36 \%$ of nonresponders and historical controls had survived at 5 years. Despite the importance of these findings, several issues remained unaddressed after this landmark study. First and foremost, it was unclear whether the improved survival was the result of preserved vasodilator response or secondary to the long-term therapy with calcium channel blockers. Second, patients outside the spectrum of idiopathic PH were not examined, and thus the applicability of testing to the larger population of patients encompassed in the modern classification of $\mathrm{PH}^{21,22}$ remained unclear. This question is particularly important considering recent data suggesting that vasodilator testing may have utility in patients with nonidiopathic disease such as $\mathrm{PH}$ from congenital heart disease ${ }^{23}$ and chronic thromboembolic disease. ${ }^{24}$ Third, as Sitbon et al. demonstrated, many of those patients identified by vasodilator challenge to be early responders to calcium channel blockers did not sustain benefits over the long term. ${ }^{25}$ This finding, as well as recent therapeutic advances, makes it unclear whether the use of more modern medical therapies would offset the prognostic ability of vasodilator testing. Finally, published studies have used several different definitions of a "positive vasodilator response"; this has resulted in much confusion. ${ }^{26-35}$ Acceptance of the most recent standard, a drop in mean PA pressure of $\geq 10 \mathrm{~mm} \mathrm{Hg}$ coupled with mean PA pressure of $\leq 40 \mathrm{~mm} \mathrm{Hg}$, also remains far from universal. ${ }^{36}$

In light of these complexities, we designed a prospective cohort study to examine the utility of vasodilator testing with inhaled nitric oxide (iNO) to predict survival in $\mathrm{PH}$. Because of its pulmonary selectivity and its short halflife, iNO has become the favored agent for testing; our group and others have previously established the safety of its use for this indication. ${ }^{37,38}$

\section{Methods}

This study was approved by the Duke University Medical Center and the Cleveland Clinic institutional review boards. The study and manuscript are also in compliance with the provisions of the Health Insurance Portability and Accountability Act of 1996.

\section{Study Sample}

A diverse cohort of consecutive patients with newly diagnosed PH of various etiologies was enrolled between November 1998 and December 2008. Patients with known Dana Point class 2 disease (PH with a primary venous component) were excluded from analysis as prespecified. Patients underwent cardiac catheterization for vasodilator testing as part of their diagnostic workup before initiation of therapy or further clinical intervention.

\section{Hemodynamic Measurement}

All studies were conducted in the fasting state, with minimal sedation and were performed or supervised by the same primary operator (R.A.K.). If a left heart catheterization was performed, all contrast injections were performed after hemodynamic assessments were completed. Right heart catheterization was performed using a single end-hole, balloon flotation catheter (Bard Pulmonary Wedge Catheter, Medtronic, Minneapolis, MN or Balloon Wedge Pressure Catheter, Arrow International, Reading, PA). Baseline hemodynamic measurements included mean right atrial pressure; right ventricular systolic and diastolic pressures; PA systolic, diastolic, and mean pressures; mean pulmonary capillary wedge (pulmonary artery occlusive) pressure; and femoral artery systolic, diastolic, and mean pressures. Repeat measurements during drug administration included PA systolic, diastolic, and mean pressures; mean pulmonary capillary wedge pressure; and femoral artery systolic, diastolic, and mean pressures.

Blood samples were obtained from the main PA and femoral artery for calculation of the cardiac index using the Fick method at baseline and during drug administration. Systemic and pulmonary vascular resistances were calculated using standard hemodynamic equations and are presented in absolute (Wood) units.

\section{Nitric Oxide Delivery Protocol}

The techniques for delivery of nitric oxide have been well described previously. ${ }^{39}$ iNO gas (INO Therapeutics; Madison, WI) of medical-grade quality, conforming to US Food and Drug Administration standards, was used. A specialized delivery device (INOvent Delivery System, Ohmeda Inc, Madison, WI) delivered NO from source tanks to achieve proper dosing. All patients received iNO at 40 parts per million. At least 5 minutes were allowed before hemodynamic assessment was undertaken and pulmonary and femoral artery blood samples were repeatedly drawn for Fick cardiac output determination.

\section{Clinical Assessment and Follow-up}

All patients underwent full clinical evaluation at the time of initial referral for cardiac catheterization. Baseline studies included chest radiography, chest computed tomography if chest radiography was abnormal, ventilation-perfusion scanning, full pulmonary function testing, and electrocardiography. Subsequent medical therapy was administered at the discretion of the referring physicians. Patients were followed at regularly scheduled intervals and were also contacted by telephone at the completion of the study to verify vital status, initially assessed through examination of the Social Security Death Index.

\section{Statistical Analysis}

Data are presented as mean \pm standard deviation for continuous variables and as a percentage for discrete variables. Comparison of dichotomous variables was performed using the Pearson chisquared test or Fisher's exact test where appropriate. Comparisons of continuous variables between groups were performed using 2 -sided $t$-tests. The Kaplan-Meier method was used to compute unadjusted survival functions and the difference was tested using a log-rank test. Multivariate analysis was performed using Cox proportional hazards, and inclusion in the model was determined by significance on univariate analysis as well as the external clinical judgment of the investigators. The proportional hazards assumption was tested and upheld graphically. For all tests 
Table 1. Baseline Characteristics of Pulmonary Hypertensives Stratified by Vital Status at Completion of Follow-up Period

\begin{tabular}{|c|c|c|c|c|}
\hline Demographics & All Patients $(\mathrm{n}=197)$ & Survivors $(\mathrm{n}=146)$ & Deaths $(\mathrm{n}=51)$ & $P$ Value \\
\hline Age (y) & $56.4(14.6)$ & $54.3(14.3)$ & $62.2(14.1)$ & $<.01$ \\
\hline Female $(\%)$ & 72 & 72 & 73 & 1.00 \\
\hline Race $(\%)$ & & & & .58 \\
\hline Caucasian & 80 & 81 & 77 & \\
\hline African American & 17 & 16 & 22 & \\
\hline Other & 3 & 3 & 2 & \\
\hline Modified Dana Point Classification (\%) & & & & .92 \\
\hline Class 1 & 68 & 67 & 69 & \\
\hline Class 3 & 20 & 20 & 22 & \\
\hline Class 4 & 4 & 4 & 4 & \\
\hline Class 5 & 8 & 9 & 6 & \\
\hline Idiopathic pulmonary hypertension (\%) & 43 & 43 & 41 & .87 \\
\hline $\mathrm{WHO}$ class $\geq \mathrm{III}(\%)$ & 68.4 & 62.0 & 87.5 & $<.01$ \\
\hline Systemic hypertension (\%) & 33 & 34 & 29 & .61 \\
\hline Diabetes $(\%)$ & 17 & 16 & 20 & .67 \\
\hline Atrial fibrillation (\%) & 14 & 12 & 22 & .10 \\
\hline Serum sodium (mg/dL) & $139.0(3.3)$ & $139.3(3.0)$ & $138.3(4.1)$ & .11 \\
\hline Serum creatinine (mg/dL) & $1.0(0.4)$ & $1.0(0.4)$ & $1.1(0.4)$ & .01 \\
\hline Arterial oxygen saturation (\%) & $89.0(14.8)$ & $89.9(14.3)$ & $86.9(15.8)$ & .32 \\
\hline $\begin{array}{l}\text { At least } 1 \text { pulmonary } \\
\text { hypertension drug }(\%)^{*}\end{array}$ & 60 & 60 & 61 & 1.00 \\
\hline Combination pulmonary hypertension drug $(\%)^{*}$ & 17 & 19 & 12 & .28 \\
\hline
\end{tabular}

Continuous variables are presented as mean values (standard deviations).

Bold values indicate statistical significance.

*Percent of patients started on pulmonary hypertension-specific therapy during follow-up.

a $P$ value $<.05$ was considered statistically significant. Data were analyzed and compiled using JMP 8.0 software (SAS Institute, Inc, Cary, NC).

\section{Results}

\section{Patient Demographics and Baseline Hemodynamics}

Catheterization and nitric oxide challenge were performed on 214 patients. Fifteen patients were excluded for predominately pulmonary venous hypertension (Dana Point class 2). Two patients were excluded because operators were unable to enter the pulmonary artery because of severe anatomic distortion: one patient with pulmonary atresia and 1 with congenitally corrected transposition who experienced ventricular tachycardia during catheter manipulation. Final analysis was conducted using the remaining 197 patients. There were 51 deaths (25.9\%) over a mean follow-up period of 2.3 years. The demographics of the entire population, stratified by their vital status at the completion of the follow-up period, are listed in Table 1 .
The cohort of decedents was older $(62.2 \pm 14.4$ years vs. $54.3 \pm 14.3$ years, $P<.01)$ and had more progressive functional impairment compared to survivors (World Health Organization class $\geq$ III, 87.5 vs. $62.0 \%, P<.01)$. Decedents also had a higher serum creatinine than survivors $(1.1 \pm 0.4$ vs. $1.0 \pm 0.4 \mathrm{mg} / \mathrm{dL}, P=.01)$. The distribution of pulmonary hypertension classifications did not appear different between decedents and survivors (Dana Point class 1/3/4/5, 69/22/4/6 vs. $67 / 20 / 4 / 9 \%, P=.92)$, nor did the distribution of patients with idiopathic PH (43.2 vs. $41.2 \%, P=.87$ ).

Baseline hemodynamic values, stratified by vital status, are listed in Table 2. Decedents had higher RA pressure $(12.5 \pm 6.6$ vs. $9.3 \pm 5.5 \mathrm{~mm} \mathrm{Hg}, P<.01)$ and mean PA pressure (49.6 \pm 16.9 vs. $44.4 \pm 15.5 \mathrm{~mm} \mathrm{Hg}, P=.05)$ than survivors, though cardiac index was similar $(2.3 \pm$ 0.9 and $\left.2.5 \pm 0.9 \mathrm{~L} \cdot \min \cdot \mathrm{m}^{2}, P=.14\right)$.

\section{Response to Nitric Oxide Challenge}

The mean reduction in PA pressure during iNO compared with baseline was $14.1 \pm 12.6 \%$ in the entire population and the median reduction was $13.3 \%$ (interquartile

Table 2. Baseline Hemodynamic Values stratified by Survivors Versus Deaths

\begin{tabular}{lcrr}
\hline Demographics & All Patients $(\mathrm{n}=197)$ & Survivors $(\mathrm{n}=146)$ & Deaths $(\mathrm{n}=51)$ \\
\hline RA pressure, $\mathrm{mm} \mathrm{Hg}$ & $10.2(5.9)$ & $9.3(5.5)$ & $12.5(6.6)$ \\
PA pressure, $\mathrm{mm} \mathrm{Hg}$ & $45.8(15.7)$ & $44.4(15.5)$ & $49.6(15.9)$ \\
Cardiac index, $\mathrm{L} / \mathrm{m}^{2} / \mathrm{min}$ & $2.5(0.9)$ & $2.5(0.9)$ & $2.3(0.9)$ \\
PVR, Wood units & $9.1(7.2)$ & $8.4(7)$ & .01 \\
SVR, Wood units & $22.2(9.1)$ & $22.3(9.2)$ & .14 \\
Vasodilator responder $(\%)$ & 39.1 & 46.6 & .11 \\
\hline
\end{tabular}

RA, right atrium; PA, pulmonary arterial; PVR, pulmonary vascular resistance; SVR, systemic vascular resistance.

Continuous variables are presented as mean values (standard deviations).

Bold values indicate statistical significance. 


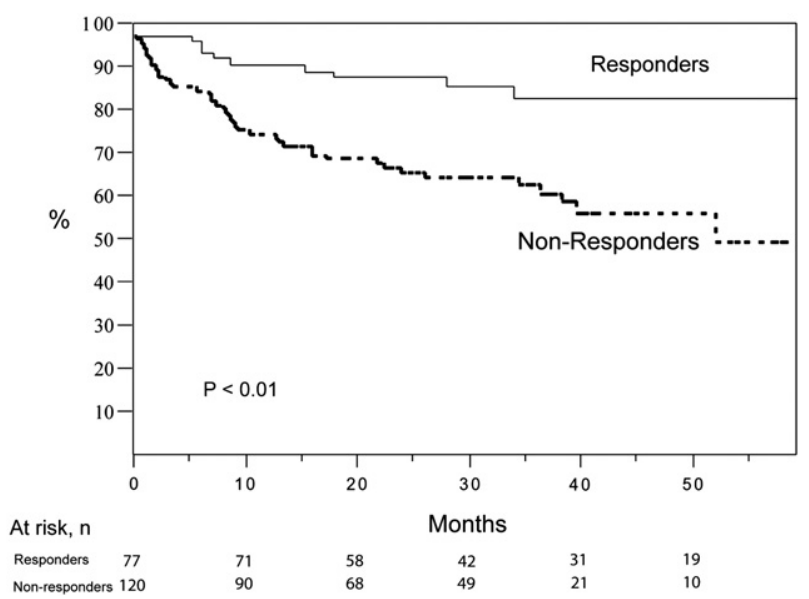

Fig. 1. Kaplan-Meier survival analysis of all patients dichotomized by vasodilator response.

range: $0.05 \%$ to $22.7 \%$ ). When stratified according to vital status, a trend toward greater reduction in PA pressure $(15.6 \pm 12.6 \%$ vs. $9.7 \pm 11.5 \%, P<.01)$ was seen in patients who survived compared to those who died. PA pressure reduction did not appear to vary according to $\mathrm{PH}$ classification.

We chose to define vasodilator responders as those participants who achieved both a PA pressure $\leq 40 \mathrm{~mm} \mathrm{Hg}$ and at least the median reduction in PA pressure of the cohort $(13.3 \%)$. Kaplan-Meier survival analysis of the entire cohort demonstrates improved survival for vasodilator responders versus non-responders $(P<.01$, Fig. 1). Furthermore, being a vasodilator responder predicted improved survival regardless of whether the patient had idiopathic or nonidiopathic $\mathrm{PH}(P=.02, P<.01$; Fig. 2$)$, and whether or not they had Dana Point Class 1 or non-Dana Point Class 1 PH $(P<.01, P=.01$; Fig. 3$)$.

Clinical characteristics are stratified by vasoreactivity in Table 3. Vasodilator responders were less likely to receive PH-specific therapy (39\% vs. $73 \%, P<.01)$ or a combination of PH-specific therapies $(9.1 \%$ vs. $22.5 \%, P=.02$.
Vasodilator responders also had significantly lower RA pressures $(7.8 \pm 4.2 \mathrm{~mm} \mathrm{Hg}$ vs. $11.7 \pm 6.4 \mathrm{~mm} \mathrm{Hg}$, $P<.01)$, lower PA pressures $(39 \pm 10.6$ vs. $50.1 \pm$ $16.9, P<.01)$, lower PVR $(6.6 \pm 5$ Woods Units vs. $10.7 \pm 8$ Woods Units, $P<.01$ ), and a higher cardiac in$\operatorname{dex}(2.8 \pm 0.9$ vs. $2.3 \pm 0.9, P<.01)$.

The variables included in the proportional hazards model were: age, baseline RA pressure, serum creatinine, function class, diagnostic class, and whether or not the participant was a vasodilator responder (Table 4). In the final model advanced age, elevated right atrial pressure, elevated serum creatinine, and worsened functional class significantly predicted shorter survival $(P=.01, P=.01, P=.01, P<$ .01 ), whereas vasodilator response predicted improved survival with a hazard ratio of $0.35(P=.01$, Table 3$)$. The addition of whether or not a patient received pulmonary arterial hypertension-specific therapy to the model did not appear to significantly alter the results, and had a nonsignificant parameter effect (HR 0.7, 95\% CI 0.37-1.33, $P=.26)$.

\section{Treatment During Follow-Up}

The most commonly used pharmacologic agents in descending order of frequency included warfarin (49.3\%), continuous flow oxygen $(34.0 \%)$, angiotensin-converting enzyme inhibitors or angiotensin II receptor blockers (29.8\%), epoprostenol (20.3\%), sildenafil (27.4\%), spironolactone $(21.3 \%)$, bosentan $(19.3 \%)$, statins $(19.8 \%)$, digoxin (14.2\%), treprostinil (8.1\%), and iloprost (3.0\%). The prevalence of $\mathrm{PH}$-specific pharmacologic therapy during follow-up was not significantly different between survivors and decedents (Table 1). Four patients proceeded to lung transplantation during follow-up.

\section{Discussion}

This study demonstrates that even in the context of more modern medical therapy, a drop in PA pressure with nitric oxide predicts an improved clinical outcome in patients

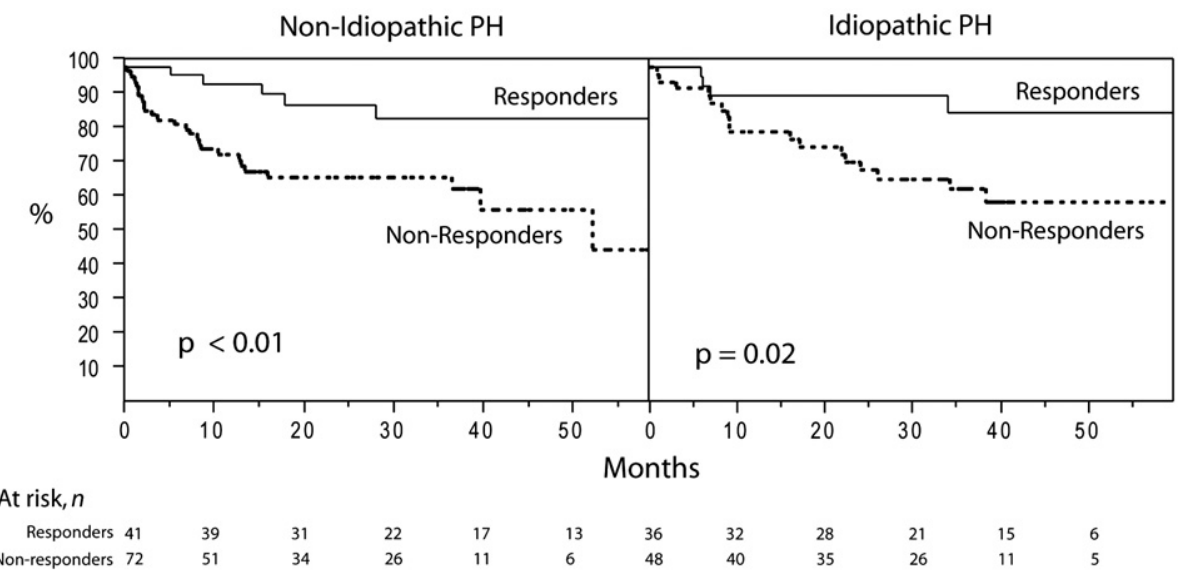

Fig. 2. Kaplan-Meier survival analysis of patients with both nonidiopathic and idiopathic pulmonary hypertension dichotomized by vasodilator response. 


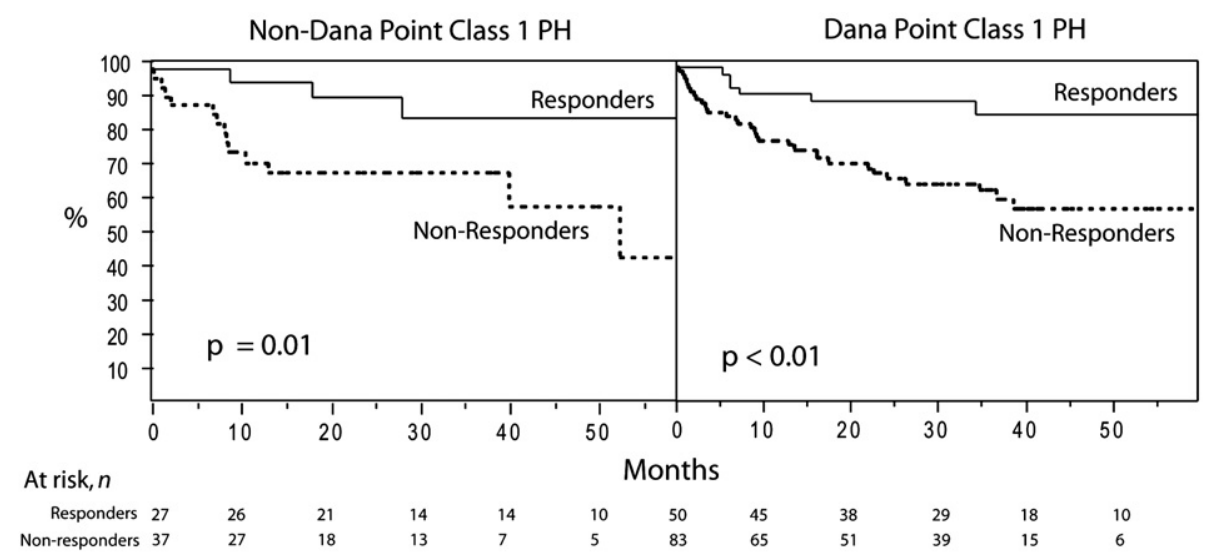

Fig. 3. Kaplan-Meier survival analysis of patients with both non-Dana Point class 1 and Dana Point class 1 pulmonary hypertension dichotomized by vasodilator response.

with treatment-naive PH. This difference was not only present in patients with idiopathic $\mathrm{PH}$, but was similarly predictive of clinical outcome in nonidiopathic PH. Furthermore, vasodilator response predicted improved survival in both Dana Point class $1 \mathrm{PH}$ and non-Dana Point class $1 \mathrm{PH}$. These findings suggest that vasoreactivity is a meaningful parameter for risk stratification, not only in those patients with idiopathic $\mathrm{PH}$, but for the larger group of patients with PH of any classification (excluding those with pulmonary venous hypertension, Dana Point class II).

The cut point we used to define vasodilator responders was at least a $13.3 \%$ drop in PAP (the median reduction) to a value $\leq 40 \mathrm{~mm} \mathrm{Hg}$. Patients that met these criteria for vasodilator response experienced one-third the mortality of non-responders over a mean of 2.3 years. Not only did this trend hold true regardless of the etiology of $\mathrm{PH}$, but vasodilator response was found on multivariate analysis to be a strong predictor of improved survival even after adjustment for differences in age, creatinine, hemodynamics, function class, and diagnostic class. Therefore we maintain that vasodilator responsiveness has clinical utility for stratifying risk of mortality in a wider range of PH etiologies than those previously considered. It is also of note that this cut point identifies a larger group of vasodilator responders than other standards (such as a drop of $10 \mathrm{~mm}$ $\mathrm{Hg}$ to $<40 \mathrm{~mm} \mathrm{Hg}$ ), and therefore may be selecting a broader group of patients that could potentially benefit from modern therapies. The application of this cut point, of course, must be validated in another cohort.

Because referring physicians were not blinded to testing results, confounding through therapy selection remains possible. Of note, no significant differences were seen between

Table 3. Clinical Characteristics Stratified by Vasoreactivity

\begin{tabular}{|c|c|c|c|c|}
\hline Demographics & All Patients $(\mathrm{n}=197)$ & Responders $(\mathrm{n}=77)$ & Nonresponders $(\mathrm{n}=120)$ & $P$ Value \\
\hline Age (y) & $56.4(14.6)$ & $55.6(14.7)$ & $56.8(14.8)$ & .56 \\
\hline Female $(\%)$ & 72 & 66 & 75 & .14 \\
\hline Race (\%) & & & & .9 \\
\hline Caucasian & 80 & 81 & 78 & \\
\hline African American & 17 & 16 & 18 & \\
\hline Other & 3 & 3 & 4 & \\
\hline Modified Dana Point Classification (\%) & & & & .42 \\
\hline Class 1 & 68 & 65 & 69 & \\
\hline Class 3 & 20 & 21 & 20 & \\
\hline Class 4 & 4 & 3 & 5 & \\
\hline Class 5 & 8 & 11 & 6 & \\
\hline Idiopathic PH (\%) & 43 & 43 & 40 & .39 \\
\hline WHO Class $\geq$ III (\%) & 68.4 & 61 & 74 & .08 \\
\hline RA Pressure, mm Hg & $10.2(5.9)$ & $7.8(4.2)$ & $11.7(6.4)$ & $<.01$ \\
\hline PA pressure, $\mathrm{mm} \mathrm{Hg}$ & $45.8(15.7)$ & $39(10.6)$ & $50.1(16.9)$ & $<.01$ \\
\hline Cardiac index, $\mathrm{L} / \mathrm{m}^{2} / \mathrm{min}$ & $2.5(0.9)$ & $2.8(0.9)$ & $2.3(0.9)$ & $<.01$ \\
\hline PVR, Wood units & $9.1(7.2)$ & $6.6(5)$ & $10.7(8)$ & $<.01$ \\
\hline SVR, Wood units & $22.2(9.1)$ & $20.9(9.3)$ & $23.1(8.9)$ & .14 \\
\hline At least $1 \mathrm{PH}$ drug $(\%)^{*}$ & 60 & 39 & 73 & $<.01$ \\
\hline Combination PH drug (\%)* & 17 & 9.1 & 22.5 & .02 \\
\hline
\end{tabular}

RA, right atrium; PA, pulmonary arterial; PH, pulmonary hypertension; PVR, pulmonary vascular resistance; SVR, systemic vascular resistance; WHO, World Health Organization.

Continuous variables are presented as mean values (standard deviations)

*Percent of patients started on $\mathrm{PH}$-specific therapy during follow-up. 
Table 4. Proportional Hazards Regression Model

\begin{tabular}{lccr}
\hline Variable & Hazard Ratio & $95 \%$ CI & $P$ Value \\
\hline Age & 1.03 & $1.01-1.05$ & $\mathbf{. 0 1}$ \\
Baseline RA pressure (mm Hg) & 1.07 & $1.02-1.12$ & $\mathbf{. 0 1}$ \\
Serum creatinine (mg/dL) & 2.20 & $1.18-3.68$ & $\mathbf{0 . 0 1}$ \\
WHO class & 3.24 & $1.46-8.63$ & $<. \mathbf{0 1}$ \\
Dana Point Class I & 1.21 & $0.66-2.36$ & $\mathbf{. 5 3}$ \\
Vasodilator vesponder & 0.35 & $0.14-0.74$ & $\mathbf{. 0 1}$ \\
\hline
\end{tabular}

RA, right atrium; PA, pulmonary arterial; WHO, World Health Organization. Bold values indicate statistical significance.

the therapies utilized in responders and nonresponders, though this not surprising given that the variety of different therapies used limits the power to detect any meaningful survival differences within and between drug classes. Additionally, only $36 \%$ of patients with Dana Point Class 1 disease received pulmonary arterial hypertension specific therapy. Though the untreated patients may account for deaths that are independent of vasodilator response, treatment was not a predictor of death in multivariate modeling and the percentage of untreated patients was nearly identical between survivors and decedents $(40 \%$ and $39 \%$, respectively; $P=1.0$ ). Another possible limitation of this study is that selection bias influenced referral for vasodilator testing. This could have affected the degree of vasodilator responsiveness and limited the applicability of the results. Of note it is standard practice at our institutions for all patients undergoing right heart catheterization for suspected or known $\mathrm{PH}$ to undergo vasodilator testing at the time of initial cardiac catheterization. A concerted effort was made to recruit all such patients referred for testing during the enrollment period, and the result is a diverse population of patients with $\mathrm{PH}$. Additionally, enrollment in this study also occurred over a 10-year period, during which standard therapy changed significantly.

Because most previous studies have focused on patients with idiopathic $\mathrm{PH}$ or $\mathrm{PH}$ resulting from collagen vascular disease, this study provides novel information about a larger and previously understudied population of patients, those with PH of other etiologies. It is hoped that these findings will stimulate further research on the role of vasodilator challenge and its utility in identifying those patients who will benefit from therapy. Furthermore, a growing body of literature suggests use of endothelin antagonists, ${ }^{40-42}$ phosphodiesterase inhibitors, ${ }^{43-45}$ prostaglandins, ${ }^{46}$ and combinations thereof ${ }^{47,48}$ may improve $\mathrm{PH}$ outcomes in these patients. These findings are further supported by a recent meta-analysis showing that these targeted therapies do in fact improve survival. ${ }^{49}$ Our results suggest that vasodilator testing continues to have prognostic utility, even with the advent of modern therapy. The mortality in this study (26\% overall and $35 \%$ in nonresponders) again underscores the serious nature of a diagnosis of pulmonary hypertension. Clearly, there remains a continued need for investigation into the etiology of and therapeutic approach towards PH. In the meantime, vasodilator testing appears to be a very formidable manner of risk-stratifying patients with $\mathrm{PH}$ of various etiologies and identifying those patients at greatest need for aggressive medical therapy or consideration for lung or combined heart-lung transplantation.

\section{Acknowledgments}

The authors would like to acknowledge the efforts of Cynthia Pierce, RN, Abby Krichman, RN, Susie McDevitt, RN, Leslie Miller, RRT, Michael Holocker, BS, RRT, William Wilk, BS, RRT, and Michelle Johnson, RN, for their technical assistance in this project.

\section{Disclosures}

Richard Krasuski has served as a consultant to Actelion and Gore Medical and is on the speakers bureaus of Actelion, AGA Medical, Pfizer, Roche, and United Therapeutics. No outside financial support was received to conduct this investigation.

\section{References}

1. Budhiraja R, Tuder RM, Hassoun PM. Endothelial dysfunction in pulmonary hypertension. Circulation 2004;109:159-65.

2. Cella G, Bellotto F, Tona F, et al. Plasma markers of endothelial dysfunction in pulmonary hypertension. Chest 2001;120:1226-30.

3. Farber HW, Loscalzo J. Pulmonary arterial hypertension. New Engl J Med 2004;351:1655-65.

4. Rich S, Dantzker DR, Ayres SM, et al. Primary pulmonary hypertension. A national prospective study. Ann Intern Med 1987;107:216-23.

5. Barst RJ, Rubin LJ, Long WA, et al. A comparison of continuous intravenous epoprostenol (prostacyclin) with conventional therapy for primary pulmonary hypertension. The Primary Pulmonary Hypertension Study Group. New Engl J Med 1996;334:296-302.

6. McLaughlin VV, Genthner DE, Panella MM, Rich S. Reduction in pulmonary vascular resistance with long-term epoprostenol (prostacyclin) therapy in primary pulmonary hypertension. New Engl J Med 1998;338:273-7.

7. Olschewski H, Simonneau G, Galie N, et al. Inhaled iloprost for severe pulmonary hypertension. New Engl J Med 2002;347:322-9.

8. McLaughlin VV, Sitbon O, Badesch DB, et al. Survival with first-line bosentan in patients with primary pulmonary hypertension. Eur Resp J 2005;25:244-9.

9. Rubin LJ, Badesch DB, Barst RJ, et al. Bosentan therapy for pulmonary arterial hypertension. New Engl J Med 2002;346:896-903.

10. McLaughlin VV, Gaine SP, Barst RJ, et al. Efficacy and safety of treprostinil: an epoprostenol analog for primary pulmonary hypertension. J Cardiovasc Pharmacol 2003;41:293-9.

11. Channick RN, Simonneau G, Sitbon O, et al. Effects of the dual endothelin-receptor antagonist bosentan in patients with pulmonary hypertension: a randomised placebo-controlled study. Lancet 2001; 358:1119-23.

12. Liu C, Cheng J. Endothelin receptor antagonists for pulmonary arterial hypertension. Cochrane Database Systemic Ref 2005;(1). CD004434.

13. Skoro-Sajer N, Lang I. The role of treprostinil in the management of pulmonary hypertension. Am J Cardiovasc Drugs 2008;8:213-7.

14. Sastry BK, Narasimhan C, Reddy NK, Raju BS. Clinical efficacy of sildenafil in primary pulmonary hypertension: a randomized, placebo-controlled, double-blind, crossover study. J Am Coll Cardiol 2004;43:1149-53. 
15. Singh TP, Rohit M, Grover A, Malhotra S, Vijayvergiya R. A randomized, placebo-controlled, double-blind, crossover study to evaluate the efficacy of oral sildenafil therapy in severe pulmonary artery hypertension. Am Heart J 2006;151:851.e851-5.

16. Benedict N, Seybert A, Mathier MA. Evidence-based pharmacologic management of pulmonary arterial hypertension. Clin Therapeutics 2007;29:2134-53.

17. Nagaya N. Drug therapy of primary pulmonary hypertension. Am J Cardiovasc Drugs 2004;4:75-85.

18. Atwood CW Jr, McCrory D, Garcia JG, Abman SH, Ahearn GS. American College of Chest Physicians. Pulmonary artery hypertension and sleep-disordered breathing: ACCP evidence-based clinical practice guidelines. Chest 2004;126:72Se7S.

19. Badesch DB, Abman SH, Ahearn GS, et al. Medical therapy for pulmonary arterial hypertension: ACCP evidence-based clinical practice guidelines. Chest 2004;126:35S-62S.

20. Rich S, Kaufmann E, Levy PS. The effect of high doses of calciumchannel blockers on survival in primary pulmonary hypertension. New Engl J Med 1992;327:76-81.

21. Simonneau G, Galie N, Rubin LJ, et al. Clinical classification of pulmonary hypertension. J Am Coll Cardiol 2004;43:5S-12S.

22. Simonneau G, Robbins IM, Beghetti M, et al. Updated clinical classification of pulmonary hypertension. J Am Coll Cardiol 2009;54:S43-54.

23. Post MC, Janssens S, Van de Werf F, Budts W. Responsiveness to inhaled nitric oxide is a predictor for mid-term survival in adult patients with congenital heart defects and pulmonary arterial hypertension. Eur Heart J 2004;25:1651-6.

24. Ulrich S, Fischler M, Speich R, Popov V, Maggiorini M. Chronic thromboembolic and pulmonary arterial hypertension share acute vasoreactivity properties. Chest 2006;130:841-6.

25. Sitbon O, Humbert M, Jais X, et al. Long-term response to calcium channel blockers in idiopathic pulmonary arterial hypertension. Circulation 2005; 111:3105-11.

26. Leuchte HH, Schwaiblmair M, Baumgartner RA, Neurohr CF, Kolbe T, Behr J. Hemodynamic response to sildenafil, nitric oxide, and iloprost in primary pulmonary hypertension. Chest 2004;125: $580-6$.

27. Morales-Blanhir J, Santos S, de Jover L, et al. Clinical value of vasodilator test with inhaled nitric oxide for predicting long-term response to oral vasodilators in pulmonary hypertension. Respir Med 2004;98: 225-34.

28. Raffy O, Azarian R, Brenot F, et al. Clinical significance of the pulmonary vasodilator response during short-term infusion of prostacyclin in primary pulmonary hypertension. Circulation 1996;93:484-8.

29. Ricciardi MJ, Knight BP, Martinez FJ, Rubenfire M. Inhaled nitric oxide in primary pulmonary hypertension: a safe and effective agent for predicting response to nifedipine. J Am Coll Cardiol 1998;32: $1068-73$.

30. Roberts DH, Lepore JJ, Maroo A, Semigran MJ, Ginns LC. Oxygen therapy improves cardiac index and pulmonary vascular resistance in patients with pulmonary hypertension. Chest 2001;120:1547-55.

31. Sitbon O, Brenot F, Denjean A, et al. Inhaled nitric oxide as a screening vasodilator agent in primary pulmonary hypertension. A doseresponse study and comparison with prostacyclin. Am J Resp Crit Care Med 1995;151:384-9.

32. Sitbon O, Humbert M, Jagot JL, et al. Inhaled nitric oxide as a screening agent for safely identifying responders to oral calcium-channel blockers in primary pulmonary hypertension. The Eur Resp J 1998; 12:265-70.

33. Ghofrani HA, Wilkins MW, Rich S. Uncertainties in the diagnosis and treatment of pulmonary arterial hypertension. Circulation 2008;118: 1195-201.

34. Skoro-Sajer N, Hack N, Sadushi-Kolici R, et al. Pulmonary vascular reactivity and prognosis in patients with chronic thromboembolic pulmonary hypertension: a pilot study. Circulation 2009;119: 298-305.

35. Archer SL, Michelakis ED. An evidence-based approach to the management of pulmonary arterial hypertension. Curr Opin Cardiol 2006; 21:385-92.

36. Barst RJ, McGoon M, Torbicki A, et al. Diagnosis and differential assessment of pulmonary arterial hypertension. J Am Coll Cardiol 2004; 43:40S-7S.

37. Krasuski RA, Warner JJ, Wang A, Harrison JK, Tapson VF, Bashore TM. Inhaled nitric oxide selectively dilates pulmonary vasculature in adult patients with pulmonary hypertension, irrespective of etiology. J Am Coll Cardiol 2000;36:2204-11.

38. Pepke-Zaba J, Higenbottam TW, Dinh-Xuan AT, Stone D, Wallwork J. Inhaled nitric oxide as a cause of selective pulmonary vasodilatation in pulmonary hypertension. Lancet 1991;338:1173-4.

39. Wessel DL, Adatia I, Thompson JE, Hickey PR. Delivery and monitoring of inhaled nitric oxide in patients with pulmonary hypertension. Crit Care Medi 1994;22:930-8.

40. Oudiz RJ, Galie N, Olschewski H, et al. Long-term ambrisentan therapy for the treatment of pulmonary arterial hypertension. J Am Coll Cardiol 2009;54:1971-81.

41. Chen YF, Jowett S, Barton P, et al. Clinical and cost-effectiveness of epoprostenol, iloprost, bosentan, sitaxentan and sildenafil for pulmonary arterial hypertension within their licensed indications: a systematic review and economic evaluation. Health Technol Assess 2009;13: $1-320$.

42. Galie N, Rubin L, Hoeper M, et al. Treatment of patients with mildly symptomatic pulmonary arterial hypertension with bosentan (EARLY study): a double-blind, randomised controlled trial. Lancet 2008;371: 2093-100.

43. Montani D, Chaumais MC, Savale L, et al. Phosphodiesterase type 5 inhibitors in pulmonary arterial hypertension. Adv Ther 2009;26:813-25.

44. Archer SL, Michelakis ED. Phosphodiesterase type 5 inhibitors for pulmonary arterial hypertension. N Engl J Med 2009;361:1864-71.

45. Jing ZC, Jiang X, Wu BX, et al. Vardenafil treatment for patients with pulmonary arterial hypertension: a multicentre, open-label study. Heart 2009;95:1531-6.

46. Barst RJ, Gibbs JS, Ghofrani HA, et al. Updated evidence-based treatment algorithm in pulmonary arterial hypertension. J Am Coll Cardiol 2009;54:S78-84.

47. Simonneau G, Rubin LJ, Galie N, et al. Addition of sildenafil to longterm intravenous epoprostenol therapy in patients with pulmonary arterial hypertension: a randomized trial. Ann Intern Med 2008;149: 521-30.

48. Taichman DB. Therapy for pulmonary arterial hypertension: the more, the merrier? Ann Intern Med 2008;149:583-5.

49. Galie N, Manes A, Negro L, Palazzini M, Bacchi-Reggiani ML, Branzi A. A meta-analysis of randomized controlled trials in pulmonary arterial hypertension. Eur Heart J 2009;30:394-403. 